\title{
Open Access Transition: A view through the lens of a librarian
}

\author{
Barbara Laner \\ Open Access Contact Point, Digital Services Department, University and State Library of Tyrol \\ Barbara.Laner@uibk.ac.at
}

\begin{abstract}
20 years after international initiatives agreed in a joint effort to convert the scientific publishing system to open access, the transformation has come to a standstill. Despite the establishment of open access strategies and open access offices at universities, a large proportion of publications remain not openly accessible. Initiatives such as Plan S, founded by a group of research funders, are trying to accelerate the open access transformation, putting pressure on commercial scientific publishers. Whether this can succeed depends not only on the participation of the scientific institutions, but above all on the strengthening of community-based and science-led initiatives and infrastructures with the aim of making the publishing sector as a whole fairer, more sustainable and more transparent.
\end{abstract}

\section{Keywords}

Open Access, Plan S, Commercial Publishing, Alternative Publishing Systems

\section{Open Access-Transformation: ein Blick durch die Linse einer Bibliothekarin}

\section{Zusammenfassung}

20 Jahre nachdem sich internationale Initiativen und Deklarationen in einer gemeinsamen Anstrengung zur Umstellung des wissenschaftlichen Publikationswesens auf Open Access geeinigt haben, ist die Transformation ins Stocken geraten. Trotz der Etablierung von Open Access-Strategien und Open Access-Koordinationsstellen an Universitäten, bleibt ein Großteil der Publikationen nicht offen zugänglich. Neue Initiativen wie Plan S, die von einer Gruppe Forschungsförderern gegründet wurde, versuchen nun mit Druck, auch auf kommerzielle Wissenschaftsverlage, die Open Access-Transformation zu beschleunigen. Ob dies gelingen kann, hängt nicht nurvon der Beteiligung der Wissenschaftseinrichtungen ab, sondern vor allem von der Stärkung von gemeinschaftsbasierten und wissenschaftsgeleiteten Initiativen und Infrastrukturen mit dem Ziel, den Publikationssektor insgesamt gerechter, nachhaltiger und transparenter zu gestalten.

\section{Schlüsselwörter}

Open Access, Plan S, kommerzielle Wissenschaftsverlage, alternative Publikationssystem

The author has declared that no competing interests exist. 


\section{Introduction: 20 years of open access movement}

In view of the digital turn and the World Wide Web, the euphoria about the emerging innovative possibilities of electronic and online publishing and its sustainable impact and improvement of scientific communication was omnipresent. This led to the Budapest Open Access Initiative of 2002 as well as the Berlin Declaration of 2003. Both initiatives have not lost any of their urgency - to make publicly funded research results available for anyone. Still, little did change in the traditional scientific publishing system, i.e. in the way research outputs are communicated, and even though open access publishing has been well received and established in almost all disciplines, a great part of research results is still hidden behind a paywall.

Now, almost two decades later, most universities have adopted an open access policy, established publication funds and implemented open access strategies along with open access offices. Despite these developments and despite the growing number of open access agreements with publishers as well as detailed studies on the transformation process, we still seem far from a complete and global open access transformation. In fact, the asymmetry within the scientific publishing system seems to be growing due to the globally unbalanced distribution of publishing agreements and with regard to different disciplinary practices.

This discussion will highlight the perspectives of national and international funders as well as of institutional open access strategies and open access offices in Austria. I would like to point out the dilemma of the commercialization of open access and the current incentive system. First, I will outline the establishment of open access strategies at Austrian universities that has led to an increase in open access research output. The intricate connection between the commercialization of the publishing system and the open access movement is worth discussing in order to understand why we seem to have come to a standstill. Thirdly, Plan S stands for an exemplary initiative of an ambitious yet to some extent unilateral route to accelerate the open access transformation that may bring a push towards open access, but that might deepen certain trenches. As the last aspect, I would like to focus on the so-called alternative publication system and the importance of science-led infrastructures.

\section{The institutionalization of open access}

The implementation of open access strategies at institutional level has occupied Austrian universities and research institutions over the past decade. Most universities have adopted open access strategies, including policies, open access offices as central and strategic contact points, and established publication funds. The University of Innsbruck, for instance, published its open access policy in March 20I7, a month after the open access contact point was officially launched.

An important aspect of the open access strategy is the systematic negotiation of open access agreements with major publishers. In Austria, most university libraries have joined forces in the KEMÖ (Kooperation E-Medien Österreich) in order to achieve a better negotiating position with commercial science publishers for the coordinated acquisition and licensing of electronic resources, in particular of electronic subscription journals. Nowadays, these negotiations include open access deals with the aim of enabling university members to publish open access free of charge and of avoiding double payments to the publishers. Hence, the respective open access publication fees are set off against the subscription fees, for which different calculation and licensing models exist (for an overview see Kromp/Koren-Wilhelmer 20I9). In addition to the large commercial publishers, university presses and medium-sized publishers are also pushing into the open access market to compete for the budgets of libraries.

Open access agreements have created a new area of responsibility for libraries by bringing libraries closer to the publication process of researchers: standardized workflows have been developed for the validation of eligible open access publications, monitoring of (open access) publications as well as advice and support for researchers in relation to open access are taking on greater importance. As a result, university libraries have a greater influence on the publication activity of researchers, which entails more responsibility in terms of a clear position on open access, participation in institutional policies, but also the need for transparency. In addition to open access negotiations, libraries have implemented institutional repositories to enable researchers disseminating works online that were previously hidden. Publication funds for open access articles and technical and financial support of open access journals published by university presses complement the institutional open access support.

At national level, the commitment towards open access reflects in the open access policy of the Austrian Science Fund, which has been advocating strict open access guidelines for years. The "Recommendations for the Transition to Open Access in Austria" published by the Open Access Network Austria in 2016 were adopted for the "Austrian European Research Area Roadmap" (2016) aiming at complete open access publishing by 2025. In addition, "Austrian Transition to Open Access (AT2OA)" (2017-2020), a cooperation project across Austrian Universities funded by the federal ministry, contributes to the national transformation from closed to open access. 
The national strategy is also reflected in the performance agreements with universities and research institutions. The intellectual capital report of the University of Innsbruck (2020, I85) shows an overall open access rate for all publications recorded for the reporting year 2019 of $30 \%$ (or $50 \%$ if only the publications recorded on Web of Science (WoS) are counted, i.e. publications mainly in the disciplines of physics and astronomy, biology, and chemistry). Considering that further open access agreements have been concluded, most notably with Elsevier, the share of open access publications will continue to increase, but these agreements will serve certain disciplines more than others, as the WoS share shows. How is it that almost two decades after the Budapest Declaration we are still a long way from a complete transformation towards open access and that a large part of research results is still behind a paywall (which is particularly, but not only, critical in times of a pandemic)?

The development towards the open access paradigm seems to have increased in complexity rather than leading to a substantial transformation of the academic publishing sector. There are two reasons why the transition is not progressing as quickly as anticipated in the declarations. One is the commercialization of open access as part of the commercialization of the academic publishing system as a whole, and the other is the prestige economy when assessing research performance, as in bibliometric indices like the impact factor.

\section{The commercialization of (open access) pub- lishing}

Already in the 1990s, the so-called serials crisis put library budgets under stress. Subscription costs for renowned journals of commercial publishers, especially scientific, technical and medical journals, led to subscription price increases far beyond the inflation rate (Dewatripont 2006, 5). With the onset of electronic journals, what libraries paid for the subscription to printed journals is now to be paid in the form of licences for the access to electronic journals, which are usually purchased as packages. As the libraries primarily have to guarantee the supply of literature, e.g. in the form of subscription journals, the introduction of the open access paradigm did so far not bring any relief to the library budget. Instead, the large commercial academic publishers invented an additional source of income in the form of the article processing charge (APC). Considering that digital publishing is more cost-effective in terms of layout and distribution, and considering that researchers hardly ever receive any remuneration as authors, editors or reviewers, but that institutions pay for reading or publication fees or both, the commercial publishing system has become more than cynical.
Consequently, without cost-effective agreements with publishers and without incentives for researchers, open access is neither feasible nor acceptable. University libraries have begun to negotiate open access agreements as part of the contracts with the major publishers within consortia, as already mentioned in the example of KEMÖ. In 2015, the Max Planck Digital Library's White Paper calculated that there is enough money in the publishing system to enable a large-scale transformation to open access. The authors conclude that only when all subscription costs stop and the money is reinvested in a broad range of publishing services, will the open access transition be successful (Schimmer/Geschuhn/Vogler 2015, II). For a transition study within the $\mathrm{AT}_{2} \mathrm{OA}$ project, which focuses on the budgetary consequences of an increase in open access publications at Austrian universities, Fessler $(2019,47)$ concludes that without a global transformation to open access, it is more likely that the traditional subscription model will continue to exist alongside open access in the long term.

Funding agencies that distribute taxpayers' money for excellent research have adopted open access policies at an early stage. Funding mandates for openly accessible research publications as well as research data resulting from funded projects influence the publishing market, even more so when funders join forces as in $\mathrm{cO}-$ Alition S. Can initiatives like Plan S change the scientific publishing system in the long term? Or do they rather reinforce the global asymmetry within the system?

\section{Plan S: acceleration towards open access}

In September 2018, cOAlition S, a group of several national and European funders - among them the Austrian Science Fund - announced an ambitious plan to accelerate the open access transformation. Under the auspices of Science Europe and Jan-Robert Smits, the outgoing open access envoy of the European Commission, cOAlition S published the ten key principles of Plan S. This was followed by detailed guidelines, a call for feedback, several discussion loops and the postponement of deadlines, with the final launch date now set at I January 202I. The initial reactions of the stakeholders involved varied. On the one hand, some researches criticized the restriction of academic freedom. On the other hand, institutions feared to be confronted with additional administrative burdens.

As the launch date approaches and (media) attention has decreased, other funding agencies and charitable organizations have joined cOAlition S, while others have left the coalition. In the meantime, the coalition has developed a rather pragmatic rights retention strategy to support researchers to retain their intellectual ownership rights of their accepted manuscript version. In 
addition, they announced a journal checker tool to help researchers identify Plan S compliant journals. Most importantly, they established the price transparency framework, which urges publishers to break down the costs of APCs by disclosing how much is charged for each service. These are promising strategies, but even though the importance of a diversity of business models is acknowledged, the focus is on transformative agreements with the major commercial publishers.

Two arguments of this discussion on Plan S are worth exploring in more detail and in a global perspective. First, the aspect of academic freedom and, second, the latent prevalence of the APC business model in the concept of transformative agreements. Researchers have regularly criticized that open access mandates violate their academic freedom and the free choice of the scientific journal. It did not come as a surprise that this argument was put forward against Plan S (for instance in an open letter by the Swedish biochemist Lynn Karmelin as well as in a statement by the German Chemical Society). In the summer of 2020, the European Research Council, one of the founding members of cOAlition S, withdrew its support arguing that Plan S was especially detrimental to early-stage researchers if "hybrid venues outside of transformative arrangements will be 'non-compliant'" (ERC 2020). This demonstrates that what the success of early-stage researchers actually depends on, are publications in so-called high-ranking journals.

This line of argument thus reveals another dilemma that is detrimental not only to young researchers but to the entire open access transformation process itself: the impact factor and similar journal-based metrics. As long as research output is measured, evaluated and rewarded on the basis of citation indices at journal level, there is little incentive to publish in (and thus establish) new (open access) journals. If we reverse the argument, why does the impact factor not threaten academic freedom and the free choice of journals?

Although the journal impact factor has recently come under increasing criticism, high value is still attributed to the prestige of a journal. Unless open access is recognized as one indicator for research assessment, and unless more balanced evaluation criteria and metrics are used to assess high-quality research, Plan S and similar initiatives will remain a powerful yet niche framework limited to third party funded projects. The Austrian Science Fund and other members of the cOAlition $S$ have therefore signed the Declaration on Research Assessment (DORA) and integrated it in the principles of Plan S. It is desirable that universities and research institutions will follow suit.

The second aspect of Plan S concerns the focus on transformative agreements with publishers and their underlying APC business model. Obviously, cOAlition $S$ needs to involve the major publishers in Plan $S$ for a full transformation of the market. Therefore, Plan S-compliant publications in subscription journals with an open access option will only be compliant if the journal or publisher enters a transformative agreement. The aim of transformative agreements is the conversion of subscription journals into fully open access journals and thus to a business model based on a fairly priced publishing fee. However, as long as commercial publishers keep total costs at this high and rising level - in the same way that costs of print subscriptions remained the basis for the electronic subscriptions - the majority of the library budget, even for fully open access journals, will continue to be consumed by a few profiteers in the publishing market.

The strongest criticism, and arguably the most valid set of arguments in this regard, comes from researchers and supporters of open science infrastructures in the Global South. For instance, representatives of the South American organisations AmeliCA and CLACSO point to the global imbalance caused by the APC pay-to-publish models as funding is unevenly directed to the commercial publishers leading to the underfunding of community-based infrastructure (Babini 2020, 2; Becerril García 2020, 57).

A global open access transformation therefore requires a more equitable system in which different open access approaches are equally supported and each institution contributes according to size, staff and budget. A system that takes into account different disciplinary publishing practices, and that measures and evaluates research results according to a more diverse bibliometric system. Above all, a system in which the sovereignty of publishing lies in the hands of those to whom it belongs: the researchers and institutions. In the words of Becerril García: "Why not tackle the basic problem? Reduce the power of the publishing oligopoly. Take back control of the publishing industry." $(2 \mathrm{O} 2 \mathrm{O}, 57)$

\section{Towards a balanced system through scholarly- led infrastructures}

Looking at the broad categories of open access journals in combination with their different business models, a study by Keller $(2017,24,32)$ reveals the following results: While commercial open access journals are financially successful with the APC business model, the APC model has not proved viable for non-commercial and newly founded individual and university journals. Due to a lack of initial reputation and awareness, but also depending on the discipline (e.g. in the humanities or social sciences), non-commercial journals usually depend on subsidies from other sources of income, most notably a combination of institutional resources, third party funding and a lot of voluntary commitment. Soci- 
ety-based journals that want to switch to open access are in a similar dilemma: On the one hand, they are committed to open access, on the other hand, they depend on funding from their members and are dependent on the publishers who take over printing and editing and/ or own the exploitation rights $(2017,30)$.

Therefore, various strategies are needed to counter the struggle of non-commercial open access journals and publishing venues: support for sustainable publishing services as well as incentives and rewards. Institutional infrastructures (libraries, university presses, IT-services) have established supportive publishing services that can reduce costs and help professionalize the production and presentation of open access journals. However, these departments also very often have to struggle with limited human and budgetary resources and are dependent on institutional commitments. Therefore, increased institutional support as well as participation in consortia to support alternative and university-based publication venues is an urgent desideratum.

In addressing the oligopoly of a few commercial publishers who control the market and absorb the bulk of the publishing budgets of libraries and project funds, we must take into account the different publishing practices. A one-fits-all approach does not do justice to the diverse disciplinary traditions also in terms of publication formats beyond scientific articles. Scholarly-led and community-based infrastructures, which leave room for transformation and innovation, are among the most promising approaches in order to strive for a change in the publication system on a global scale. Especially for the humanities and the social sciences, this approach provides a way of "following the trails of the natural sciences again" (König 2020, 2).

In order to ensure the sustainability of collaborative and scholarly-led publication venues, the focus must be on the cost-benefit ratio. Wrzesinski $(2020,5)$ confirms that donations and sponsorship are only partially effective and lead to dependence on "good will". Ideally, support financed by the community and consortia should be provided, which is largely underdeveloped for scholarly-led journals. It is therefore crucial to raise awareness of the concerns of scholarly-led journals not funded by APCs and to promote network building. Ferus and Reckling (2019) discuss different funding models as well as necessary funding criteria and give an overview of initiatives already funded by Austrian universities and the Austrian Science Fund. Additionally, research institutions need to commit to initiatives such as DORA and implement the use and contextualization of different metrics to highlight bibliometric diversity.

Institutional, national and international cooperation with the scientific community is necessary to strive for a modern publishing system in which openness is de- fault. The pressure on commercial publishers for transparency and fair pricing must come from both research policies and the scientific community. Equally important are initiatives such as $\mathrm{OA} 2 \mathrm{O} 2 \mathrm{O}$ that are reallocating subscription funding to open access publishing as well as ESAC or OpenAPC that support the monitoring of the open access publishing market to ensure transparency and sustainability.

\section{Conclusion}

What does this mean for institutions and their open access strategies? We need a more equitable system that takes into account discipline-specific traditions, allows for innovation, strengthens science-driven initiatives, pushes for agreements that lead to actual transformation, and guarantees transparency in funding, quality assurance and performance assessment beyond a purely prestige-driven reward system.

While the ambitious Plan S will certainly lead to a further surge in open access publications of beneficiaries of project funds, the question remains whether it will enable a transformation of the publishing system towards open access on a global scale. Plan S and other open science initiatives are forcing commercial publishers to adapt. However, if we want to avoid public funds continuing to serve their profit maximization, we need an equally strong publishing sector, governed and owned by the community.

To achieve the transformation towards open access and open science on a global scale, governments, funders and institutions also need to pull in the same direction when it comes to assessing research outputs. However, the will for transformation must come primarily from the scientific communities. Only if open access is the standard scientific practice can we untie the Gordian knot, and open access will no longer be perceived as a threat to academic freedom.

\section{References}

Austrian Transition to Open Access (AT2OA) (2017-202O), Internet: https://at20a.at (access: 18.II.2020).

Babini, Dominique (2020), Rethink and Reassess the Role of Community in Post-Pandemic Open Science, conference paper, OpenAIRE Open Access Week 202O, 2I.IO.2020, online, Internet: https://doi.org/IO.528I/ zenodo.4I20843 (access: 18.1I.2O2O).

Bauer, Bruno/Guido Blechl/Christoph Bock/Patrick Danowski/Andreas Ferus/Anton Graschopf/Thomas König/ Katja Mayer/Falk Reckling/Katharina Rieck/Peter Seitz/ Herwig Stöger/Elvira Welzig (2016), Empfehlungen für die Umsetzung von Open Access in Österreich, in: 
Mitteilungen der Vereinigung Österreichischer Bibliothekarinnen und Bibliothekare, Vol. 68(3-4), 580-607.

Becerril García, Arianna (2020), Non-commercial Open Access to science, the closest approach toward sustainable and participatory scholarly communications, conference paper, Open-Access-Tage 202O, 16.09.2020, Bielefeld online, Internet: https:/doi. org/IO.528I/zenodo.4045692 (access: I8.II.2O2O).

Max-Planck-Gesellschaft (2003), Berlin Declaration on Open Access to Knowledge in the Sciences and Humanities, 22.I0.2003, Internet: https://openaccess.mpg.de/Berlin-Declaration (access: I8.II.2O2O).

Budapest Open Access Initiative (2002), I4.02.2002, Internet: https://www.budapestopenaccessinitiative.org/ read (access: 18.1I.2020).

Büro des Rektors der Universität Innsbruck (ed.) (2020), Wissensbilanz 2019: Veröffentlichte Fassung gem. § I3 (6) UG sowie der Wissensbilanzverordnung, in: Mitteilungsblatt der Leopold-Franzens-Universität Innsbruck (33), 15.05.2020, Internet: https://www.uibk.ac.at/ service/cIOI/mitteilungsblatt/2019-2020/33/mitteil. pdf (access: I8.II.2O2O).

cOAlition $S$ (2019), Accelerating the Transition to Full and Immediate Open Access to Scientific Publications, Internet: https://www.coalition-s.org/wp-content/uploads/PlanS_Principles_and_Implementation_310519.pdf (access: 18.II.2020).

Dewatripont, Mathias/Victor Ginsburgh/Patrick Legros/ Alexis Walckiers/Jean-Pierre Devroey/Marianne Dujardin/Françoise Vandooren/Pierre Dubois/Jérôme Foncel/Marc Ivaldi/Marie-Dominique Heusse (2006), Study on the economic and technical evolution of the scientific publication markets in Europe, Internet: https://ec.europa.eu/research/openscience/pdf/ openaccess/librarians_2006_scientific_pub_study. pdf (access: I8.II.2020).

European Research Council (ERC) (2020), ERC Scientific Council calls for open access plans to respect researchers' needs, 20.07.2020, Internet: https://erc. europa.eu/news/erc-scientific-council-calls-openaccess-plans-respect-researchers-needs (access: I8.II.2O2O).

Ferus, Andreas/Falk Reckling (2019), Die Förderung von alternativen, nicht-kommerziellen Open Science-Infrastrukturen \& -Services (OSIS) durch Forschungseinrichtungen in Österreich - Empfehlungen, Kriterien \& Modelle, in: Mitteilungen der Vereinigung Österreichischer Bibliothekarinnen und Bibliothekare, Vol. 72(I), 89-IO5.

Fessler, Georg (2019), Ausbau von Open Access an den österreichischen Universitäten: Budgetärer Mehrbedarf für die Jahre 2O19-2O2I. Zusammenfassung des Abschlussberichts der HRSM AT2OA-TransitionStudie, in: Mitteilungen der Vereinigung Österreichischer Bibliothekarinnen und Bibliothekare, Vol. 72(I), 35-49.
Keller, Alice (20I7), Finanzierungsmodelle für OpenAccess-Zeitschriften, in: BIBLIOTHEK - Forschung und Praxis, Vol. 4I(I), 22-35.

Kooperation E-Medien Österreich (KEMÖ), Internet: https:// www.konsortien.at/ (access: 18.II.2O2O).

König, Thomas (2020), Converting to Open Access. The Austrian Journal of Political Science (OZP) as a case study, in: Austrian Journal of Political Science, Vol. 49(3), I-6.

Kromp, Brigitte/Frank Koren-Wilhelmer (2019), Finanzierung von Open Access-Übergangsmodellen: Leitlinie für Verlagsverträge für die Open Access-Transformation, in: Mitteilungen der Vereinigung Österreichischer Bibliothekarinnen und Bibliothekare, Vol. 72(I), 66-73.

Österreichische ERA Roadmap (2016), April 2016, Internet: https://era.gv.at/object/document/258I/attach/oesterreichische_ERA_Roadmap.pdf (access: I8.II.2O20).

San Francisco Declaration on Research Assessment (DORA) (2012), I6.I2.20I2, Internet: https://sfdora.org/read/ (access: I8.II.2O2O).

Schimmer, Ralf/Kai Karin Geschuhn/Andreas Vogler (2015), Disrupting the Subscription Journals' Business Model for the Necessary Large-Scale Transformation to Open Access: A Max Planck Digital Library Open Access Policy White Paper, Internet: https://doi. org/IO.17617/I.3 (access: 18.II.2020).

Wrzesinski, Marcel (2020), Nachhaltiges Open Access: Verlagsunabhängig, divers und gebührenfrei, conference paper, Open-Access-Tage 202O, 16.09.2020, Bielefeld online, Internet: https://doi.org/I0.528I/zenodo.4062256 (access: I8.11.2020).

\section{Author}

Barbara Laner works at the University and State Library of Tyrol in the Digital Services Department where she is responsible for the open access contact point and the institutional repository. 